\title{
Spatial Patterns in Semiconductor Lasers
}

G. Khitrova, F. Brown de Colstoun, C. W. Lowry, E. M. Wright, H. M. Gibbs, Optical Sciences Center, University of Arizona. Tucson, Arizona 85721

T. M. Brennan, B. E. Hammons

Dept. 1311, Sandia National Laboratories, Albuquerque, New Mexico 87185

\begin{abstract}
.
Spatial solitons occur when an intense pulse propagates in a self-focusing semiconductor gain medium. Injecting light into a vertical-cavity surface-emitting laser causes dramatic modifications of the phase and transverse output intensity profiles, including the appearance of phase defects.
\end{abstract}

\section{DISCLAIMER}

\begin{abstract}
This report was prepared as an account of work sponsored by an agency of the United States Government. Neither the United States Gnvernment nor any agency thereof, nor any of their employees, makes any warranty, express or implied, or assumes any legal liability or responsibility for the accuracy, completeness, or usefulness of any information, apparatus, product, or process disclosed, or represents that its use would not infringe privately owned rights. Reference herein to any specific commercial product, process, or service by trade name, trademark, manufacturer, or otherwise does not necessarily constitute or imply its endorsement, recommendation, or favoring by the United States Government or any agency thereof. The views and opinions of authors expressed herein do not necessarily state or reflect those of the United States Government or any agency thereof.
\end{abstract}

All naners must include the following statement:

This work performed at Sandia National Laboratories is supported by the U.S. Deoartment of Fnergy under crniract DE.ACOA $\cdot 760$ PO0789.

\section{MASTER}




\section{Spatial Patterns in Semiconductor Lasers}

G. Khitrova, F. Brown de Colstoun, C. W. Lowry, E. M. Wright, H. M. Gibbs, Optical Sciences Center, University of Arizona, Tucson, Arizona 85721

T. M. Brennan, B. E. Hammons

Dept. 1311, Sandia National Laboratories, Albuquerque, New Mexico 87185

A beam propagating in a planar waveguide exhibits the characteristics of both a fundamental soliton (little change in waist of a $5-\mu \mathrm{m}$ beam; diffraction is compensated by selffocusing nonlinear refraction) and a second-order soliton (10- $\mu \mathrm{m}$ beam focuses to $3 \mu \mathrm{m}$ with side peaks) ${ }^{1}$. These one-dimensional spatial solitons are quite stable; bifurcations of transverse solitary wave are not seen, in sharp contrast to the case for two transverse dimensions ${ }^{2}$. Plasma-theory planar-wave beam-propagation computations agree well with the data and resemble Kerr-medium solitons ${ }^{3}$ quite closely. Thus a semiconductor gain medium in a planar waveguide is almost ideal for the demonstration of fundamental and second-order spatial solitons; it is even a candidate medium for the formation of a light bullet 4 , i.e., a soliton in space and time.

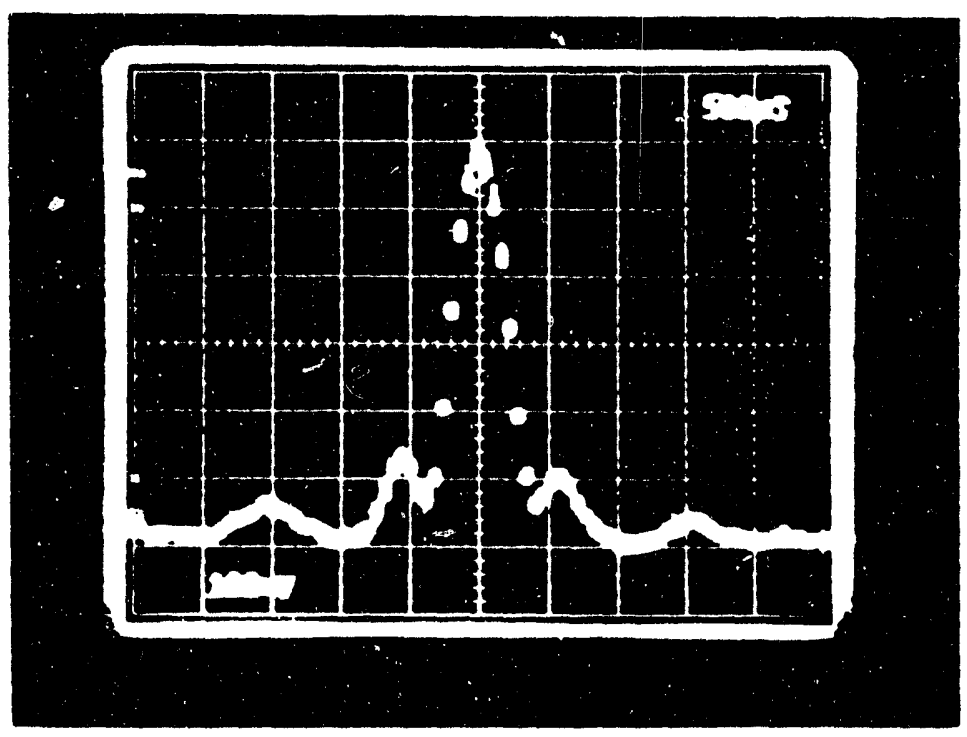

Fig. 1: Output spatial profile exhibiting a second-order spatial soliton. The input waist was $\cong 10 \mu m ; \cong 5 \mu m$ per major division. 
We have triggered transverse instabilities 5 by injecting a $\mathrm{CW}$ monochromatic $(10 \mathrm{MHz})$ beam into a vertical-cavity surface-emitting laser (VCSEL). With increased injection current, the $\mathrm{TEM}_{00}$ transverse mode changes to a combination of $\mathrm{TEM}_{00}, \mathrm{TEM}^{*}{ }_{01}$ (doughnut), and $\mathrm{TEM}_{11}$. Various transverse modes patterns can then be produced by frequency tuning the injection. Interferometrically analyzing these patterns shows that some zero-field points are field vortices ${ }^{6-9}$; see Fig. 2. The position of the vortex depends on injection frequency, power, polarization, and input position. The circulation of the phase gradient on any loop that encloses the vortex core is equal to $2 k \pi$, with $k$ (equal to one in our experiment) representing the order of the vortex, or topological charge.
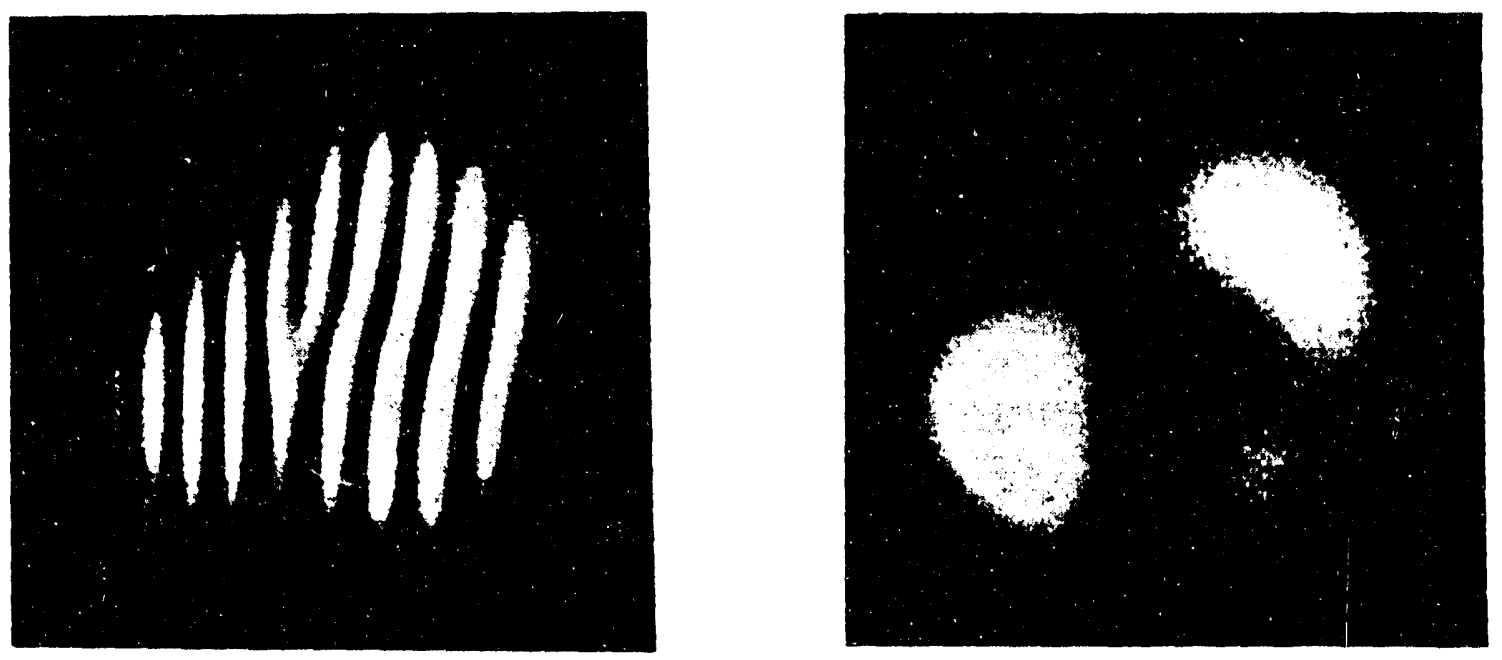

Fig.2: A phase singularity appears in the center of the interferogram of the near-field output of a VCSEL with injection (left). The corresponding intensity pattern shows a zero at the location of the phase singularity (right).

\section{References}

[1] G. Khitrova, H.M. Gibbs, Y. Kawamura, H. Iwamura, T. Ikegami, J.E. Sipe, and L. Ming, Phys. Rev. Lett. 70, 920 (1993).

[2] J.W. Grantham, H.M. Gibbs, G. Khitrova, J.F. Valley, and J. Xu, Phys. Rev. Lett. 66, 1422 (1991).

[3] S. Maneuf and F. Reynaud, Opt. Commun. 66, 325 (1988); Opt. Commun. 65, 193 (1988).

[4] Y. Silverberg, Opt. Lett. 15, 1282 (1990).

[5] L. A. Lugiato, F. Pratti, L.M. Narducci, P. Ru, J.R. Tredicce, and D.K. Bandy, Phys. Rev. A 37, 3847 (1^98).

[6] P. Coullet, L. Gil, and F. Rocca, Opt. Commun. 73, 403 (1989).

[7] F.T. Arecchi, G. Giacomelli, P.L. Ramazza, and S. Residori, Phys. Rev. Lett. 67,3749 (1991).

[8] M. Brambilla, F. Battipede, L.A. Lugiato, V. Penna, F. Pratti, C. Tamm, and C.O. Weiss, Phys. Rev. A 43, 5090 (1991).

[9] D. Dangoisse, D. Hennequin, C. Lepers, E. Louvergneaux, and P. Glorieux, Phys. Rev. A 46, 5955 (1992). 

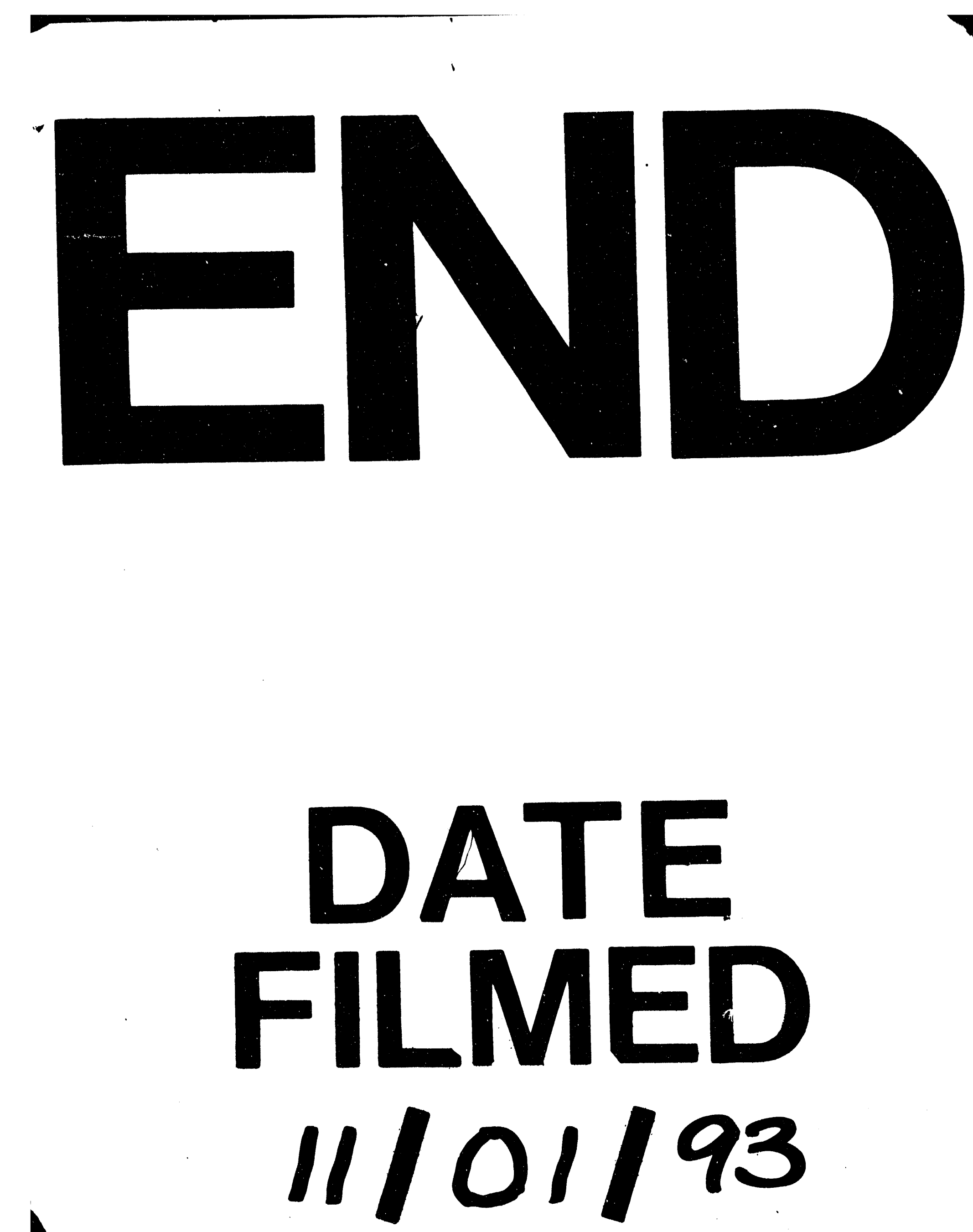

1 


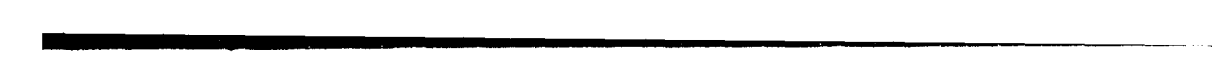

